\title{
IMPACTO FINANCEIRO DAS CONDENAÇÕES POST-MORTEM PARCIAIS E TOTAIS EM UMA EMPRESA DE ABATE DE FRANGO
}

\author{
Marina Manfroi Maschio \\ Especialista em alimentos, e-mail: m.m.maschio@hotmail.com \\ Simone Moraes Raszl \\ SENAI/SC, e-mail: simone@sc.senai.br
}

\begin{abstract}
RESUMO: A carne de frango é um produto de origem animal de boa aceitação pelo consumidor, devido seu valor nutricional e seu preço acessível. Para que a indústria avícola aumente e melhore sua eficiência em produção dentro da filosofia de melhoria contínua, é preciso diminuir suas perdas durante a produção e o processamento. Grande parte destas perdas ocorre dentro do abatedouro, principalmente envolvendo as condenações parciais e totais das carcaças. As consequências diretas se expressam principalmente em perdas de quilograma de carne efetivamente produzida. Neste sentido, este trabalho teve como objetivo analisar o impacto financeiro anual das condenações post-mortem totais e parciais em uma empresa de abate de frango, localizada na região Sul do Brasil, durante o período de um ano Também foram identificadas as principais causas destas condenações. Pode-se concluir que anualmente a empresa perde aproximadamente $\mathrm{R} \$ 1.700 .000,00$ com estas condenações e as principais causas são ascite, colibacilose, sangria inadequada, escaldagem excessiva, contaminação, contusão e fratura, artrite e dermatite.
\end{abstract}

Palavras-chave: Condenações. Abate de frango. Impacto financeiro. 


\section{INTRODUÇÃO}

O Brasil possui a extensão territorial de um continente e apresenta condições de alimentar a população brasileira e boa parte dos habitantes do planeta. A moderna avicultura brasileira, como hoje é conhecida, começou a ser desenvolvida no início da segunda metade do século passado. Até então, a atividade constituía mera pecuária de subsistência (OLIVO, 2006). Hoje, o frango é o terceiro produto da pauta agrícola de exportações brasileiras e em termos de competitividade e qualidade, o país produz hoje o frango mais barato e de melhor qualidade do mundo. O agronegócio avícola brasileiro movimenta em torno de 10 bilhões de dólares ao ano e emprega dois milhões de pessoas, em suas atividades diretas e indiretas, e tem crescido a uma taxa de $10 \%$ ao ano nas duas últimas décadas (MENDES; MACARI, 2004).

A avicultura brasileira representa hoje 1,5\% do Produto Interno Bruto nacional, gerando 4,8 milhões de empregos diretos e indiretos e acima de seis bilhões de reais apenas em impostos. Do total de carne de frango produzida, $70 \%$ são destinadas ao mercado doméstico e os $30 \%$ restantes embarcados para cerca de 150 países (UNIÃO BRASILEIRA DE AVICULTURA, 2008).

Reconhecida hoje como a mais desenvolvida do mundo, a avicultura brasileira possui índices de produtividade realmente excepcionais, com sua excelência de produção, qualidade e sanidade, oferece mundo afora produtos que atendem às necessidades de praticidade e conveniência dos mais exigentes consumidores. Estes atributos fazem do Brasil o terceiro maior produtor e líder mundial - desde 2004 - nas exportações de carne de frango, encerrando 2009 com embarques de 3,63 milhões de toneladas e receita de US\$ 5,8 bilhões (TURRA, 2010).

Este patamar foi atingido devido à implementação de programas de qualidade em todos os elos da cadeia nos últimos anos, com destaque para a genética, nutrição, manejo, biossegurança, boas práticas de produção, rastreabilidade, programas de bem-estar animal e de preservação do meio ambiente (UNIÃO BRASILEIRA DE AVICULTURA, 2008).

Esta evolução no agronegócio avícola teve como suporte a melhoria constante no desempenho das linhagens sendo, desde o início da moderna genética avícola, o aumento da taxa de crescimento dos frangos de corte, o objetivo principal a ser alcançado (SUMMERS, 1996).

Com as melhorias das práticas de melhoramento genético, nutrição, manejo e sanidade na criação de frangos de corte, aumentaram os problemas de mortalidade e perdas por condenações no abatedouro causadas por distúrbios metabólicos, diretamente relacionados aos altos níveis de produção obtidos. São as chamadas "doenças da produção". Não existe um patógeno primário envolvido, e a incidência dessas doenças está crescendo de um modo significativo em todo o mundo (BERCHIERI JR; MACARI, 2000). 
Prevenir e minimizar as patologias em frangos de corte não é só uma questão econômica, mas sim uma questão de bem-estar animal e uma questão social, uma vez que falta alimento à mesa de muitos, e, só com a sustentação da expansão concreta do setor avícola é que as empresas tem condições de participar de projetos sociais (MACHADO, 2007).

\subsection{Justificativa}

Para que a indústria avícola aumente e melhore sua eficiência em produção dentro da filosofia de melhoria contínua, é preciso diminuir suas perdas durante a produção e o processamento. Grande parte destas perdas ocorre dentro do abatedouro, principalmente envolvendo as condenações parciais e totais das carcaças. As consequências diretas que essas condenações trazem à indústria se expressam principalmente em perdas de quilograma de carne efetivamente produzida. As consequências indiretas podem comprometer ainda mais a produtividade e a rentabilidade do setor (ARISTIDES et al., 2007).

O sistema de avaliação da qualidade da carcaça e cortes de frangos é comumente baseado em critérios visuais ou estéticos, como por exemplo, conformação, presença de hemorragias e/ou hematomas, rompimento da pele, ossos quebrados e falta de partes (OLIVO, 2006).

Durante a criação dos frangos e a operação industrial, é frequente a ocorrência de lesões que acarretam em defeitos que levam a condenação de carcaças ou partes, com substanciais prejuízos para as empresas avícolas. Assim, são três as principais causas das condenações: sanitárias, manejo e operação industrial. Os defeitos de causas sanitárias são aqueles que resultam de enfermidades e lesões. Os de manejo compreendem principalmente aquelas estabelecidas pela equipe de apanha no momento do carregamento e durante o transporte. E por fim, os defeitos de origem operacional no abatedouro, são aquelas resultantes da ação de cortes realizados pelo homem ou do indevido funcionamento dos equipamentos e utensílios de abate (OLIVO, 2006).

Um dos maiores desafios da indústria brasileira é produzir alimentos em grande quantidade, com preço acessível e garantir ao consumidor um produto seguro, livre de contaminantes de natureza química, física, biológica ou qualquer outra substância que possa por em risco a saúde da população e ainda proporcionar um alimento de boa qualidade nutricional (OLIVO, 2006).

\subsection{Objetivo geral}

Este trabalho teve como objetivo geral avaliar o impacto financeiro anual de perdas por condenações post-mortem de carcaças de frango em um frigorífico localizado na região sul do Brasil, obedecendo aos critérios estipulados pelo SIF - Serviço de Inspeção Federal. 


\subsection{Objetivos específicos}

Os objetivos específicos foram:

a) Identificar as principais causas de condenação post-mortem de frangos de corte;

b) Caracterizar as condenações de maior e menor ocorrência no período de um ano.

\section{PROCEDIMENTOS METODOLÓGICOS}

O presente trabalho foi desenvolvido mediante estudo de caso, com dados de um frigorífico de Inspeção Federal localizado na região sul do Brasil, que abate diariamente em média 500.000 frangos de corte, em três linhas de abate a uma velocidade de 9.000 frangos por hora e três turnos de produção. Esta indústria é habilitada pelo SIF e classificada como estabelecimento exportador pelo MAPA.

Para a avaliação do impacto financeiro das condenações post-mortem totais, foi analisada a quantidade abatida, o peso médio do frango vivo, o rendimento médio da carcaça após o abate, o custo de produção por quilo de frango e o percentual de condenação. Entende-se por rendimento médio da carcaça após o abate, a quantidade de carne in natura após a retirada do sangue, pena, cabeça, pés, pescoço e vísceras. Os dados, todos disponibilizados pela empresa, estão presentes nas Tabelas 1, 2 e 3. A fórmula utilizada para o cálculo foi a seguinte:

$$
\begin{aligned}
& \text { I.F. = Q.A* P.M. * R.M.C. * C.P. * \% C, onde: } \\
& \text { I.F. }=\text { Impacto financeiro; } \\
& \text { Q.A. }=\text { Quantidade abatida; } \\
& \text { P.M. }=\text { Peso médio do frango vivo; } \\
& \text { R.M.C = Rendimento médio da carcaça após o abate; } \\
& \text { C.P. }=\text { Custo de produção por quilo de frango; } \\
& \text { \% C }=\text { Percentual de condenação. }
\end{aligned}
$$

Para as condenações post-mortem parciais, além dos dados disponíveis na Tabela 1 e 3 também foi considerado o percentual de descarte para cada tipo de condenação, conforme descrito na tabela 4. Os dados do percentual de descarte foram coletados através de um estudo interno realizado na empresa, que consistiu em pesar a carcaça 
condenada antes e depois de passar pelo Departamento de Inspeção Federal (DIF). A fórmula utilizada para o cálculo de impacto financeiro foi a seguinte:

\author{
I.F. = Q.A * P.M. * R.M.C. * C.P. * \% C * \% D, onde: \\ \% $\mathrm{D}=$ Percentual de descarte para cada tipo de condenação.
}

Os dados das condenações post-mortem totais e parciais utilizados foram coletados nos registros de ocorrência de condenações no período de julho de 2009 a junho de 2010, obedecendo aos critérios de condenação estipulados pelo SIF, onde foi possível identificar e caracterizar as condenações de maior e menor ocorrência, através de análises gráficas.

\begin{tabular}{|l|l|}
\hline Peso Médio (Kg) & 1,460 \\
\hline Rendimento Médio de Carcaça (\%) & $74,46 \%$ \\
\hline Custo de Produção (R\$̦/kg) & $\mathrm{R} \$ 1,69$ \\
Quantidade Abatida ( $\mathrm{n}^{\circ}$ frangos/ano) & 152.048 .050 \\
Condenações totais post-mortem (\%) & $0,243 \%$ \\
Condenações parciais post-mortem (\%) & $8,534 \%$ \\
\hline
\end{tabular}

Quadro 1 - Dados para avaliação do impacto financeiro das condenações post-mortem totais e parciais.

Fonte: Dados primários da pesquisa

\begin{tabular}{|l|c|c|}
\hline \multicolumn{1}{|c|}{$\begin{array}{c}\text { Tipo de condenação post- } \\
\text { mortem total }\end{array}$} & $\begin{array}{c}\text { Número de frangos } \\
\text { condenados no ano }\end{array}$ & $\begin{array}{c}\text { \% de condenação de acordo com o } \\
\text { volume de abate anual }\end{array}$ \\
\hline Escaldagem Excessiva & 43.266 & $0,028 \%$ \\
Sangria Inadequada & 53.166 & $0,035 \%$ \\
Colibacilose & 61.335 & $0,040 \%$ \\
Neoplasia & 3.170 & $0,002 \%$ \\
Dermatite & 906 & $0,001 \%$ \\
Aspecto Repugnante & 36.975 & $0,024 \%$ \\
Ascite & 98.852 & $0,064 \%$ \\
Caquexia & 1.988 & $0,001 \%$ \\
Contaminação & 27.133 & $0,018 \%$ \\
Celulite & 20.439 & $0,013 \%$ \\
Evisceração Retardada & 22.155 & $0,015 \%$ \\
\hline TOTAL & $\mathbf{3 6 9 . 3 2 5}$ & $\mathbf{0 , 2 4 3 \%}$ \\
\hline
\end{tabular}

Quadro 2 - Estratificação das condenações post-mortem totais.

Fonte: Dados primários da pesquisa 


\begin{tabular}{|l|c|c|}
\hline \multicolumn{1}{|c|}{$\begin{array}{c}\text { Tipo de condenação post- } \\
\text { mortem parcial }\end{array}$} & $\begin{array}{c}\text { Número de frangos } \\
\text { condenados no ano }\end{array}$ & $\begin{array}{c}\text { \% de condenação de acordo com o } \\
\text { volume de abate anual }\end{array}$ \\
Colibacilose & 47.060 & $0,031 \%$ \\
Contusão / Fratura & 2.665 .764 & $1,751 \%$ \\
\hline Aerossaculite & 60.238 & $0,039 \%$ \\
\hline Escaldagem Excessiva & 67.659 & $0,045 \%$ \\
\hline Neoplasia & 5.927 & $0,004 \%$ \\
\hline Abscessos & 45.693 & $0,030 \%$ \\
\hline Dermatite & 2.354 .994 & $1,551 \%$ \\
\hline Miopatia Peitoral Profunda & 433.054 & $0,283 \%$ \\
\hline Contaminação & 4.122 .872 & $2,712 \%$ \\
\hline Ascite & 87.374 & $0,057 \%$ \\
Celulite & 280.862 & $0,183 \%$ \\
\hline Artrite & 2.636 .278 & $1,736 \%$ \\
Salpingite & 11.726 & $0,008 \%$ \\
\hline Tendinite & 113.986 & $0,075 \%$ \\
\hline Sangria Inadequada & 363 & $0,000 \%$ \\
\hline TOTAL & 12.933 .850 & $\mathbf{8 , 5 3 4 \%}$ \\
\hline
\end{tabular}

Quadro 3 - Estratificação das condenações post-mortem parciais.

Fonte: Dados primários da pesquisa

\begin{tabular}{|l|c|}
\hline \multicolumn{1}{|c|}{ Tipo de condenação post-mortem parcial } & \% descartado \\
\hline Contaminação & $3,91 \%$ \\
\hline Contusão/fratura & $6,26 \%$ \\
\hline Artrite & $1,32 \%$ \\
\hline Dermatite & $3,01 \%$ \\
\hline Miopatia & $7,88 \%$ \\
\hline Celulite & $4,78 \%$ \\
\hline Tendinite & $2,15 \%$ \\
\hline Ascite & $19,46 \%$ \\
\hline Escaldagem Excessiva & $25,37 \%$ \\
\hline Aerosaculite & $32,66 \%$ \\
\hline Colibacilose & $31,20 \%$ \\
\hline Abscesso & $6,20 \%$ \\
\hline Salpingite & $31,68 \%$ \\
\hline Neoplasia & $36,09 \%$ \\
\hline Sangria Inadequada & $47,52 \%$ \\
\hline
\end{tabular}

Quadro 4 - Percentual de descarte em cada tipo de condenação post-mortem parcial.

Fonte: Dados primários da pesquisa 
Não foi foco do trabalho o estudo do impacto financeiro de condenações post-mortem de miúdos (coração, moela e fígado), pescoço e pés.

\section{RESULTADOS E DISCUSSÕES}

Entre julho de 2009 e junho de 2010, o frigorífico em estudo teve 8,75\% das suas aves abatidas condenadas, totalizando 13.303 .175 aves. Conforme apresentado na figura 1 , se considerarmos todas as condenações, 97,22\% foram condenações parciais (12.933.850 aves) e $2,78 \%$ foram condenações totais (369.325 aves).

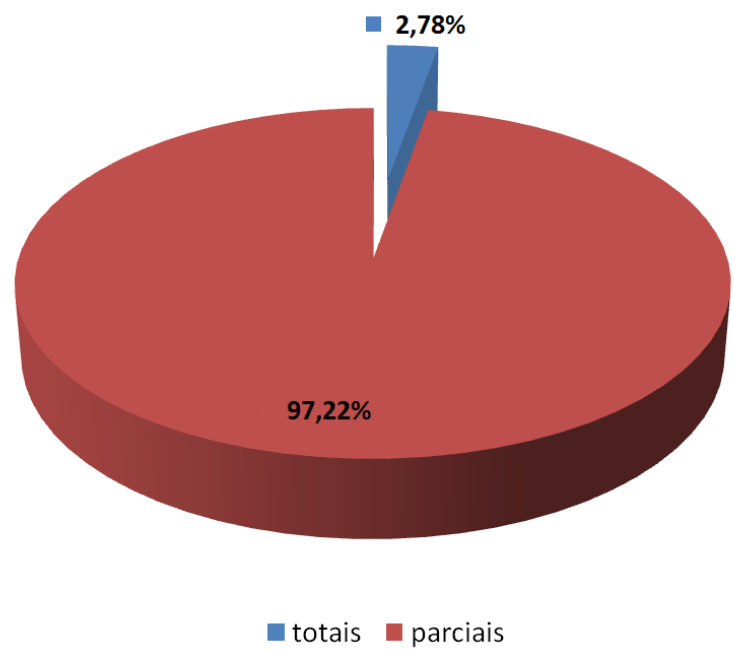

Figura 1 - Resultado das condenações post-mortem.

Fonte: Do Autor, 2010.

Considerando a quantidade abatida de 152.048 .050 frangos durante o período de um ano, o peso médio do frango de $1,460 \mathrm{~kg}$, o rendimento de carcaça de $74,46 \%$, o custo de produção de $\mathrm{R} \$ 1,69$ por quilo de frango e utilizando a fórmula:

I.F. $=$ Q.A * P.M. $*$ R.M.C. $*$ C.P. $* \%$ C,

obteve-se um impacto financeiro de $\mathrm{R} \$ \mathbf{6 7 8 . 0 8 9 , 4 5}$ durando o ano com condenações post-mortem totais de carcaças de frango.

Aplicando a análise de Pareto, observa-se que $70 \%$ das condenações post-mortem totais são representadas por ascite, colibacilose, sangria inadequada e escaldagem excessiva que juntas representaram em torno de $\mathrm{R} \$ 470.000,00$ perdidos no ano, conforme apresentado através de análise gráfica na figura 2 .

Considerando todos os motivos de condenações post-mortem totais, quatro destes, sangria inadequada, escaldagem excessiva, contaminação e evisceração retardada, são condenações de origem não patológica e poderiam ser evitadas com ações dentro 
do abatedouro, como treinamento dos sangradores e manutenção preventiva dos equipamentos. A escaldagem excessiva acontece principalmente por paradas de linha do abate por queda de energia, onde as aves ficam submersas no tanque de escaldagem com água quente. A contaminação acontece grande parte, devido às dificuldades encontradas no ajuste dos equipamentos de evisceração aos tamanhos irregulares dos frangos e por isso é necessária a regulagem constante e precisa das máquinas evisceradoras. $O$ alto índice de carcaças condenadas por sangria inadequada é devido ao fato do abatedouro possuir $100 \%$ do abate realizado por muçulmanos, impossibilitando o mesmo de ser automatizado.

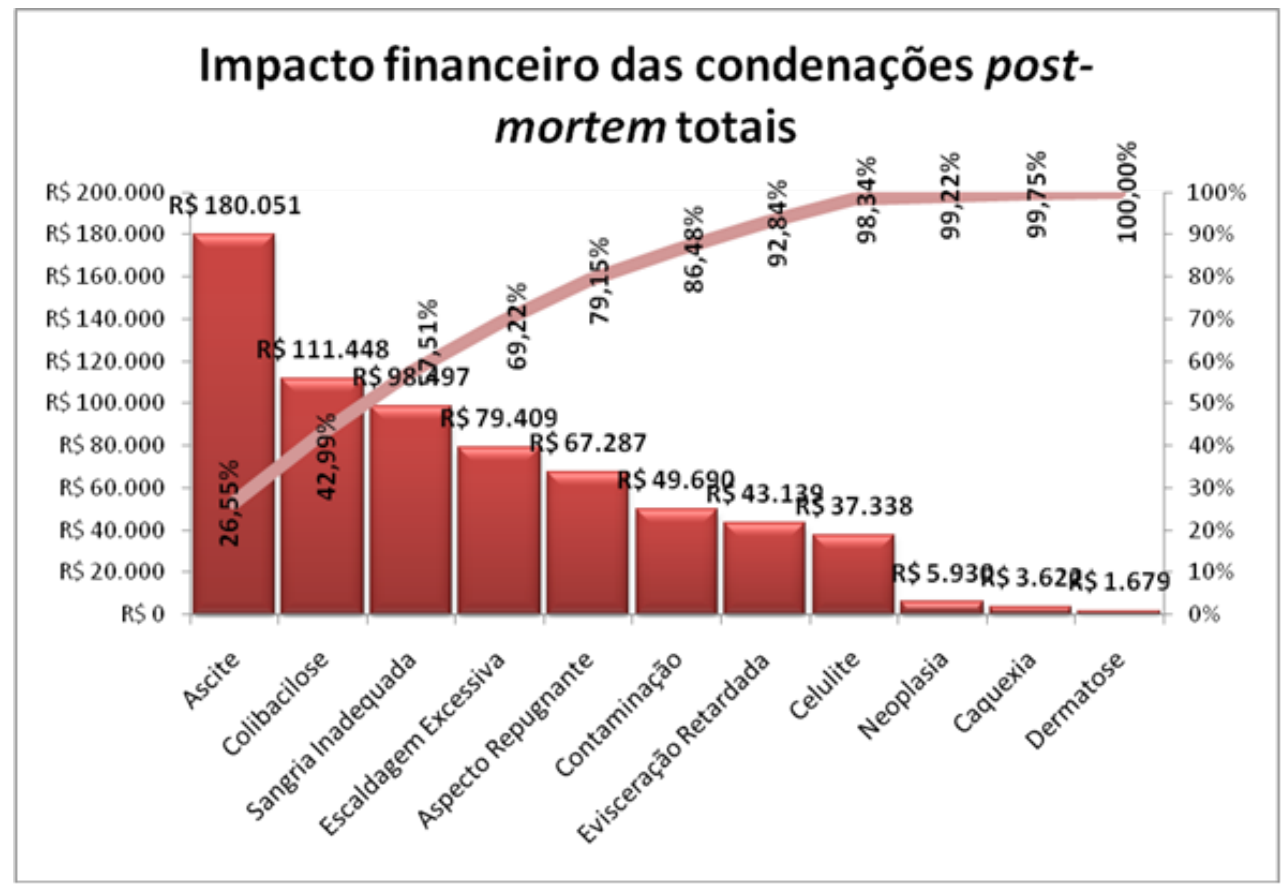

Figura 2 - Impacto financeiro das condenações post-mortem totais

Fonte: Do Autor, 2010.

Utilizando a mesma métrica de cálculo para o impacto financeiro das condenações post-mortem totais e considerando o percentual descartado para cada caso (Tabela 4) foi calculado o impacto financeiro das condenações post-mortem parciais utilizando a fórmula:

I.F. $=$ Q.A * P.M. $*$ R.M.C. * C.P. $* \%$ C $\%$ D,

onde se obteve um impacto financeiro de $\mathrm{R} \$ 1.030 .005,71$ no ano.

Observou-se também através da análise de Pareto que as condenações post-mortem parciais por contusão/fratura, contaminação e dermatite representaram juntas mais que $70 \%$ do impacto financeiro anual da empresa, totalizando $\mathrm{R} \$ \mathbf{7 3 2 . 9 3 2 , 0 0}$ (Figura 3). Porém, quando foi realizada a estratificação da quantidade de carcaças condenadas 
parcialmente por motivo, observou-se que os principais motivos respectivamente foram por contaminação, contusão/fratura e artrite (Figura 3). Esse acontecimento é relacionado à quantidade de carne descartada para cada caso de condenação postmortem parcial, pois uma carcaça com dermatite, o descarte médio é 3,01\% da carcaça e no caso da artrite $1,32 \%$.

O motivo mais impactante financeiramente para condenações post-mortem parciais é por contusão e fratura, que totalizou 2.665.764 aves, sendo o segundo maior motivo de condenações (figura 38), que pode ser reduzido através do manejo correto das aves desde a granja até o abatedouro. Estas lesões geradas dentro do abatedouro devem-se, principalmente, por má regulagem de depenadeiras e manejo incorreto de retirada de aves das gaiolas e pendura.

A condenação gerada por dermatite está relacionada com o bem-estar animal através da estrutura do aviário, temperatura ambiente, quantidade de aves armazenadas por gaiola e tempo de espera.

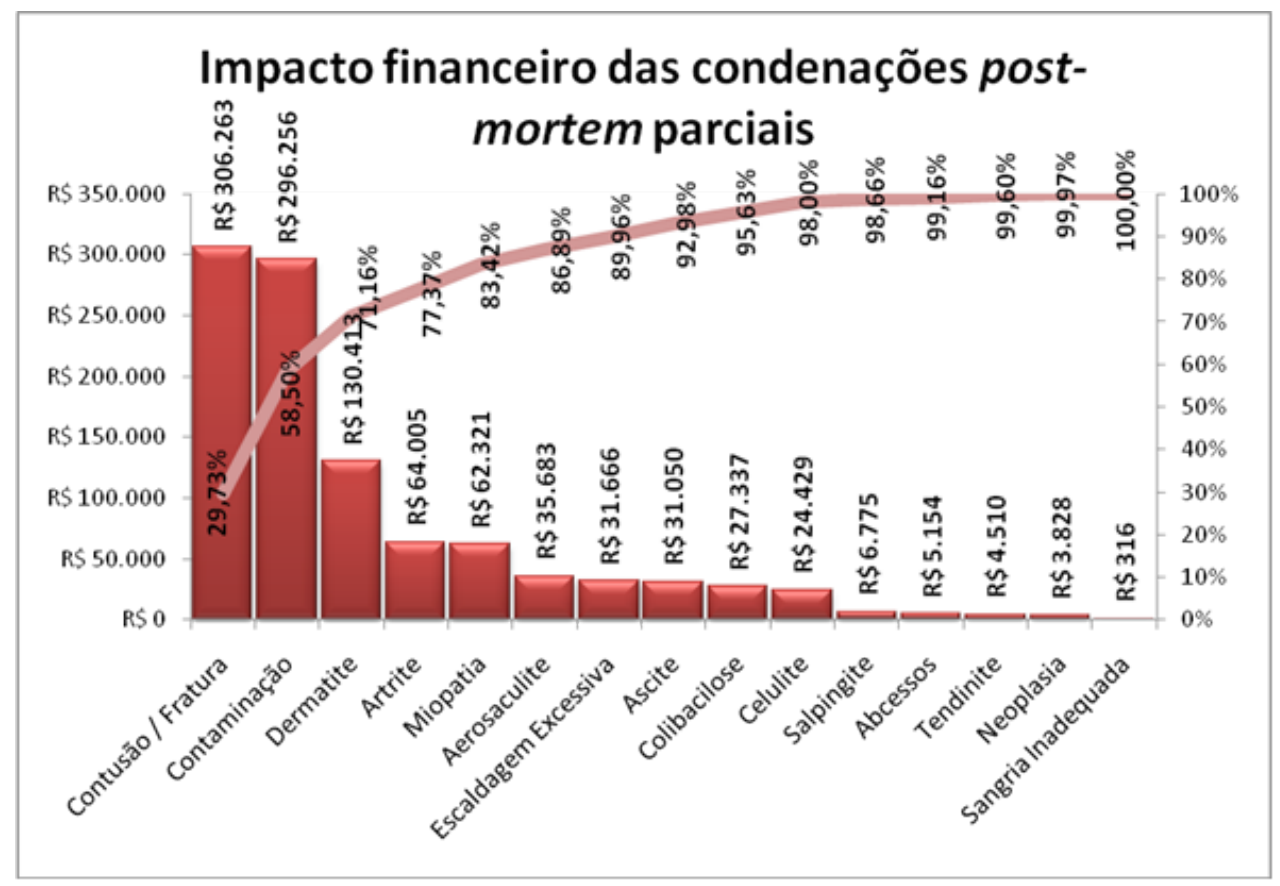

Figura 3 - Impacto financeiro das condenações post-mortem parciais

Fonte: Do Autor, 2010. 


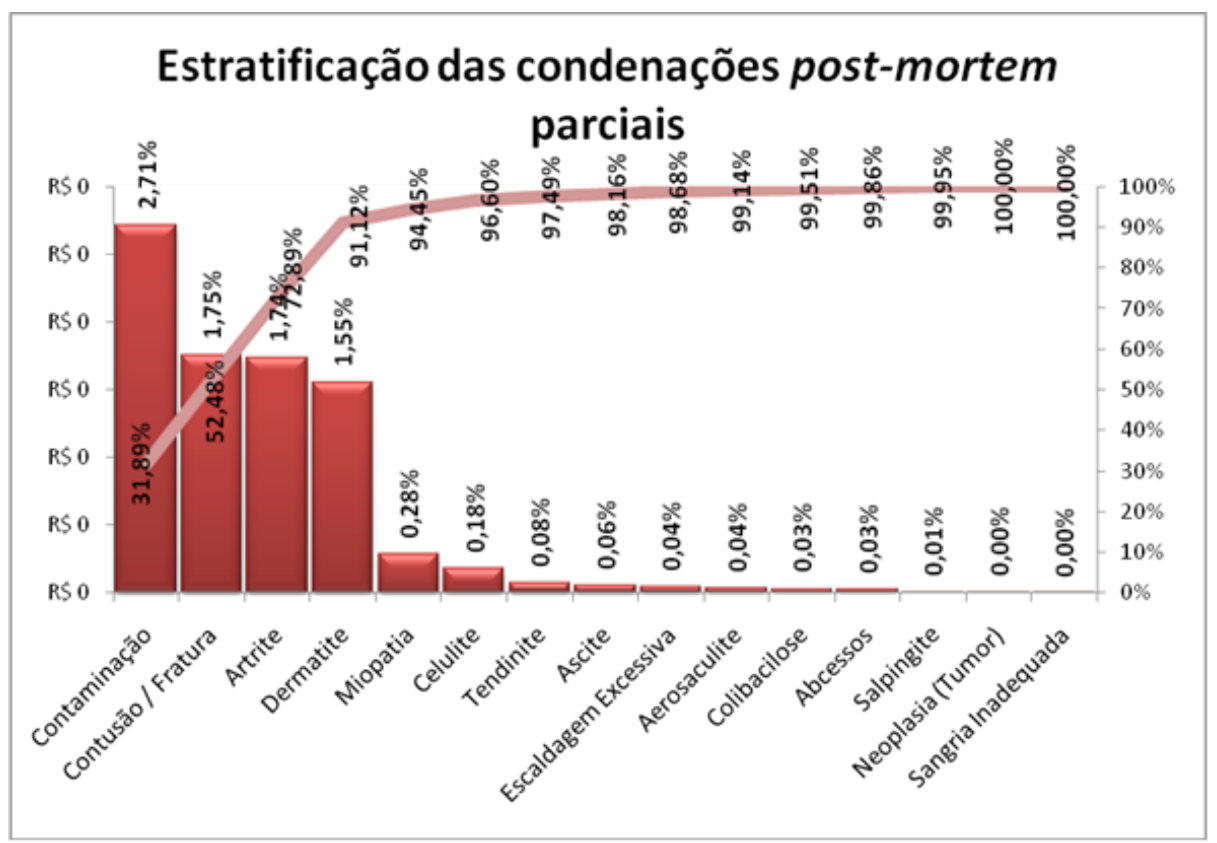

Figura 4 - Estratificações das condenações post-mortem parciais

Fonte: Do Autor, 2010.

Por fim, a figura 5, apresenta o total do impacto financeiro anual das condenações post-mortem no frigorífico em estudo, totalizando $\mathrm{R} \$ 1.708 .095,16 \mathrm{em}$ perdas financeiras anuais. Considerando o custo de produção de $\mathrm{R} \$ 1,69$ por quilo de frango, com este valor seria possível abater 1.010.707 frangos, o que representa dois dias de abate na empresa.

\section{Impacto financeiro das condenações post- mortem}

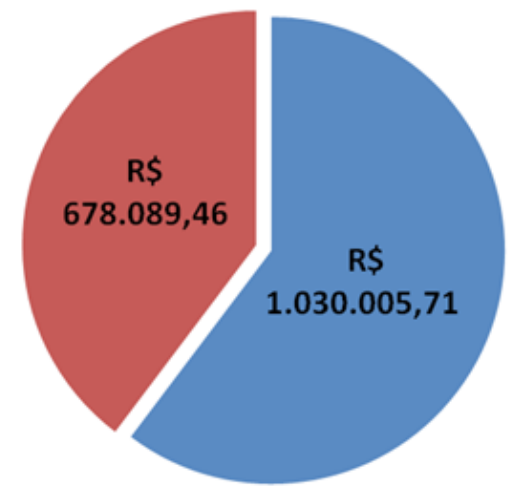

n Condenações parciais

- Condenações totais

Figura 5 - Impacto financeiro das condenações post-mortem

Fonte: Do Autor, 2010. 


\section{CONCLUSÃO}

A carne é um alimento imprescindível na composição de uma dieta que atenda as necessidades dos seres humanos e a qualidade desta carne é o principal requisito para que ela possa ser comercializada e consumida.

Neste trabalho, que tinha como objetivo principal avaliar o impacto financeiro anual de perdas por carcaças por condenações post-mortem de carcaças de frango em um frigorífico localizado na região sul do Brasil, obedecendo aos critérios estipulados pelo SIF, pode-se concluir que são perdidos $R \$ 1.708 .095,16$ anuais em condenações de carcaças, grande parte destas devido a defeitos tecnológicos dentro do abatedouro, como escaldagem excessiva total, sangria inadequada, contaminação e parte de contusão e fratura.

As condenações post-mortem totais representaram 2,78\% e as parciais, $97,22 \%$ do total condenado durante o ano, totalizando, respectivamente, um impacto financeiro de $R \$$ $678.089,45$ e $\mathrm{R} \$ 1.030 .005,71$.

As principais causas das condenações totais foram ascite, colibacilose, sangria inadequada e escaldagem excessiva e as parciais, contaminação, contusão e fratura, artrite e dermatite.

O investimento em avanços tecnológicos de modernização das granjas, equipamentos dentro do abatedouro e treinamento com os responsáveis pela apanha, transporte, pendura, sangria e manutenção e regulagem das máquinas é de suma importância, com influência direta na repercussão econômica do abatedouro, reduzindo perdas por condenações e aumentando lucro em longo prazo, não só a nível financeiro, como em nível de bem estar animal e de repercussão social. 


\title{
ECONOMIC IMPACT FROM CONVICTIONS POST-MORTEM TOTAL AND PARTIALS IN A POULTRY SLAUGHTERHOUSE
}

\begin{abstract}
The chicken meat is a product from animal origin with good acceptation by the costumers, due nutritional values and accessible prices. To the poultry industry increase and develop the efficiency about the production according with the philosophy continues, will be necessary to decrease those losses during the production and process. The biggest part of losses happens inside of slaughterhouse, mainly involving partials or totals convictions the carcass. The direct consequences expressed mainly the kilograms of losses the effective meat produced. According with this task had as objective analyses the annual financial of convictions post-mortem totals and partials from the poultry slaughterhouse, localized in south region of Brazil, during this period of the one year could be identified the principal cases of those losses. As a conclusion could check that the company losses approximate $\mathrm{R} \$ 1.700 .000,00$, with these convictions that the most of the cases are ascites, colibacillosis, inadequate bleeding, scalding excessive contamination, bruises and fractures, arthritis and dermatitis.
\end{abstract}

Keywords: convictions., chickenslaughter. financial impact.

\section{REFERÊNCIAS}

ARISTIDES et al. Diagnósticos de condenações que afetam a produtividade da carne de frangos brasileira. Revista Nacional da Carne, São Paulo, n. 368, p. 22-28, out./2007.

BERCHIERI JR, A.; MACARI, M. Doenças das Aves. Campinas, SP: FACTA, 2000.

MACHADO, F. A. Relação da condenação de carcaças de frangos de corte por síndrome da hipertensão pulmonar - SHP (ascite) - com o clima da região de São Carlos/SP, e sua repercussão econômica. 2007. 35 f. Trabalho de Conclusão de Curso (Especialização em Higiene e Inspeção em Produtos de Origem Animal e VSA) Instituto Brasileiro de Pós-Graduação em Medicina Veterinária - QUALITTAS, Campinas, 2007.

MENDES, A. A.; MACARI, M. Produção de Frangos de Corte. Campinas, SP: FACTA, 2004.

OLIVO, Rubison. (ed.) O Mundo do Frango: cadeia produtiva da carne de frango. Criciúma: Ed. do Autor, 2006.

SUMMERS, J.D. Dietary acid-base balance likely plays role in SDS, ascites. Feedstuffs, Beltsville, n. 68, 1 jan. 1996. 
TURRA, Francisco. Avicultura tem excelência em produtividade. Jornal do Comércio, Porto Alegre, n.196, p. 4-4, 03 mar. 2010. . Disponível em: <http://jcrs.uol.com.br/site/ noticia.php?codn=21544>. Acesso em: 20 nov. 2010.

UNIÃO BRASILEIRA DE AVICULTURA. Protocolo de bem-estar para frangos e perus. São Paulo, 2008. 23 p. Disponível em: <http://www.avisite.com.br/legislacao/anexos/ protocolo_de_bem_estar_para_frangos_e_perus.pdf >. Acesso em: 20 nov. 2010.

\section{SOBRE AS AUTORAS}

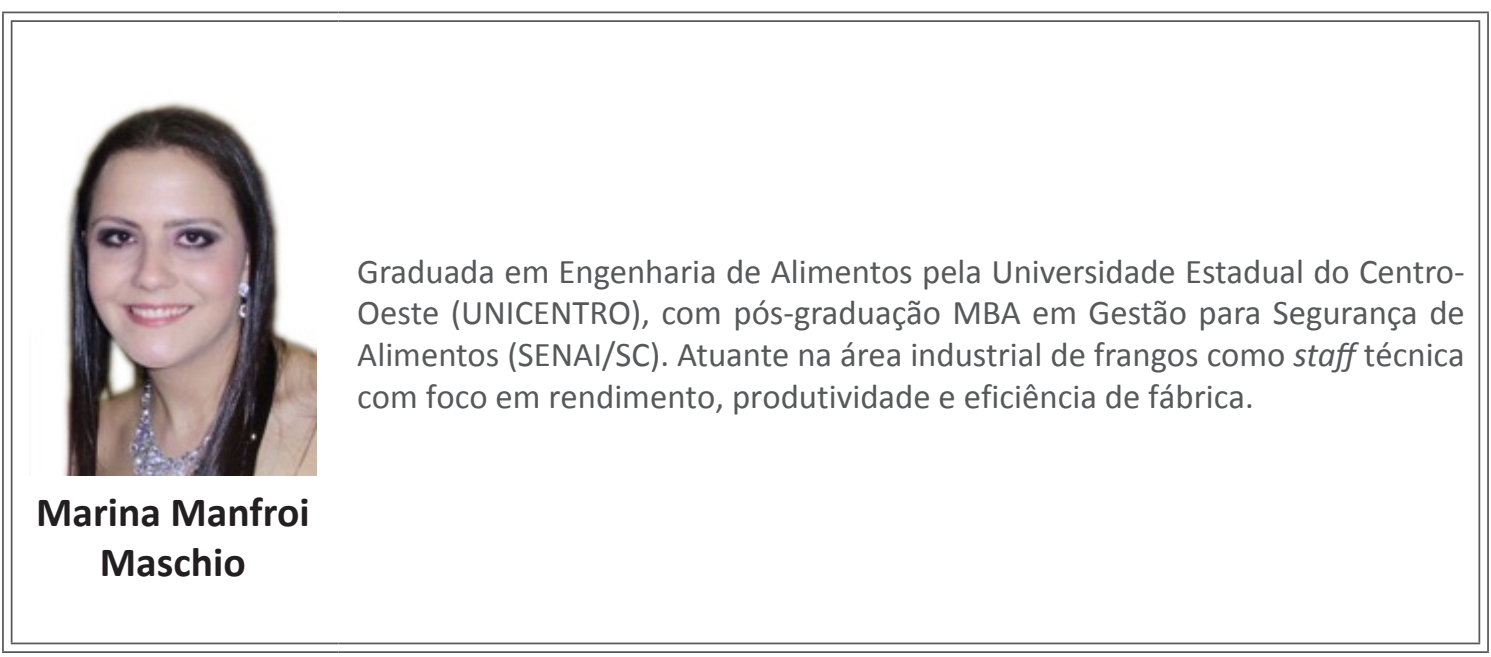

\begin{tabular}{|l} 
Médica Veterinária graduada pela Universidade Federal de Uberlândia (UFU) \\
e mestra em Ciência de Alimentos pela Universidad Autonoma de Barcelona \\
(UAB), Espanha. \\
É Lead Assessor na ISO 9001, consultora e multiplicadora do Programa Alimentos \\
Seguros (PAS) - Setor Indústria. \\
Atuou como instrutora e consultora do SENAI SC em Florianópolis para \\
implantação de Sistemas de Gestão para a Segurança de Alimentos. Foi \\
coordenadora e docente do curso de Pós-Graduação MBA em Gestão para \\
Segurança de Alimentos a distância e trabalhou na implementação e em \\
auditorias internas de Sistemas de Gestão de Qualidade e de Segurança de \\
Alimentos em diversas indústrias da área. Autora do livro Sistemas de Gestão de \\
Segurança de Alimentos, em 2008, publicado pelo SENAI e do livro Sistema de \\
Qualidade em Segurança de Alimentos: ABNT NBR ISO 22000:2006, Eurepgap \\
e BRC, publicado em 2007, pelo SENAI. Foi consultora da Organização Pan- \\
Americana da Saúde (OPAS/ OMS) em 2000-2001. \\
Atualmente é Coordenadora da Rede SENAI/SC de Educação a Distância.
\end{tabular}

